\title{
Avaliação do pigmento de Lawsonia inermis (henna) como carreador de antígenos inoculados por via transcutânea em camundongos
}

\author{
Evaluation of Lawsonia inermis (henna) pigment as a carrier of antigens inoculated \\ by transcutaneous immunization pigment in mice
}

\section{Karoline Biffi ${ }^{1}$, Alexandre Gonçalves de Rezende ${ }^{2}$, Letícia de Almeida ${ }^{3}$, Caroline Kimie Brandão Yajima ${ }^{4}$, Fernanda Cinto Barbieri ${ }^{5}$, Marcela de Lima Moreira ${ }^{6}$, Maria Cristina Lorencini de Britto ${ }^{4}$, Vanessa Lopes Rosa ${ }^{7}$, Ticiane Batista da Silva ${ }^{7}$, Tayra Ferreira Oliveira de Lima, Renata de Oliveira Santos Costa ${ }^{8}$, Pedro Eduardo Nascimento Silva Vasconcelos ${ }^{8}$, Luiz Felipe Leomil Coelho ${ }^{9}$, Luiz Cosme Cotta Malaquias ${ }^{10}$}

Mestranda em Imunologia Básica e Aplicada, Faculdade de Medicina de Ribeirão Preto, Universidade de São Paulo (USP), Ribeirão Preto, SP.

2 Mestrando em Biotecnologia pelo Programa de Biotecnologia Interunidades Instituto de Pesquisas Tecnológicas USP/Instituto Butantan, São Paulo, SP.

Mestranda em Ciências Farmacêuticas da Universidade Federal de Alfenas (UNIFAL), Alfenas, MG.

${ }^{4}$ Biotecnóloga pela UNIFAL, Alfenas, MG.

Biotecnóloga. Pesquisadora de Pesquisa e Desenvolvimento da Rheabiotech, Campinas, SP.

${ }^{6}$ Mestranda em Biologia Celular e Molecular, Centro de Pesquisas René Rachou, Fundação Oswaldo Cruz, Belo Horizonte, MG.

Acadêmicos do Curso de Biotecnologia, UNIFAL, Alfenas, MG.

Acadêmicos do Curso de Farmácia, UNIFAL, Alfenas, MG.

Doutor em Ciências Biológicas pela Universidade Federal de Minas Gerais (UFMG) e pelo Laboratoire des Défenses Antivirales et Antitumorales,

Université Montpellier II, França. Professor Adjunto do Instituto de Ciências Biomédicas da UNIFAL, Alfenas, MG.

${ }^{10}$ Doutor em Bioquímica e Imunologia pela UFMG. Professor Adjunto do Instituto de Ciências Biomédicas da UNIFAL, Alfenas, MG.

Estudo conduzido com recursos da Fundação de Amparo à Pesquisa do Estado de Minas Gerais (FAPEMIG) (APQ-01629-09) e do

Conselho Nacional de Desenvolvimento Cientifico e Tecnológico (CNPq) (501502/2009-2).

\section{RESUMO}

Objetivos: Avaliar o papel do pigmento de Lawsonia inermis (henna) como carreador de antígenos em esquema de vacinação transcutânea em camundongos.

Métodos: Camundongos foram imunizados por via transcutânea na pele do abdômen e na pele da orelha com antígeno bruto de Paracoccidioides brasiliensis e com albumina sérica bovina nas concentrações de 1,10 e $50 \mathrm{mg} / \mathrm{mL}$, por três vezes em intervalos de uma semana, na presença ou ausência de pigmentos de L. inermis. Uma semana após a última imunização, foram avaliadas a presença de anticorpos anti-antígenos no soro, das citocinas interleucina-4 e interferon- $\gamma$ e de óxido nítrico em sobrenadante de cultura.

Resultados: Não foram detectados anticorpos específicos anti-antígenos de P.brasiliensis ou albumina sérica bovina no soro. No foram encontradas diferenças significativas na produção de óxido nítrico e nos níveis de interleucina-4 e interferon- $\gamma$ em sobrenadantes de cultura celular.

Conclusões: As vacinações transcutâneas com antígeno bruto de P. brasiliensis e albumina sérica bovina em suspensão de pigmento de L. inermis não produziram resposta antigênica detectável em camundongos.

DESCRITORES: VACINAÇÃO; ADMINISTRAÇÃO TRANSCUTÂNEA; ANTICORPOS; ADJUVANTES IMUNOLÓGICOS; IMUNOADJUVANTES

\begin{abstract}
Aims: To evaluate the role of pigment Lawsonia inermis (henna) as a carrier of antigens in transcutaneous vaccination in mice.

Methods: Mice were immunized transcutaneously into the skin of the abdomen and the ear's skin with crude antigen of Paracoccidioides brasiliensis and with bovine serum albumin at concentrations of 1,10 and $50 \mathrm{mg} / \mathrm{mL}$, three times at one week intervals in the presence or absence of pigments L. inermis. One week after last immunization, the animals were evaluated for the presence of serum antibodies, interleucin- 4 and interferon- $\gamma$ cytokines, and nitric oxide in culture supernatants.

Results: No specific antibodies were detected to P. brasiliensis or bovine serum albumin antigens. There were no significant differences in the production of nitric oxide, interleucin-4 and interferon- $\gamma$ in supernatants of cell culture. Conclusions: Transcutaneous immunization with crude antigen of $P$. brasiliensis or bovine serum albumin suspended in pigment of $L$. inermis produced no detectable antigenic response in mice.
\end{abstract}

KEY WORDS: VACCINATION; TRANSCUTANEOUS ADMINISTRATION; ANTIBODIES; ADJUVANTS, IMMUNOLOGIC; IMMUNOADJUVANTS 


\section{INTRODUÇÃO}

Vacinas são instrumentos eficientes na prevenção de doenças causadas por agentes infecciosos. Entretanto, a indução de uma resposta imune adequada sem efeitos adversos significativos representa um grande desafio ao seu desenvolvimento. ${ }^{1}$ Para o sucesso de uma vacina é necessário introduzir os antígenos vacinais dentro do sítio anatômico onde eles irão interagir com células do sistema imune. A via de administração é, dessa forma, crítica para o resultado da vacinação. A via intramuscular e a subcutânea de injeção de antígenos são as mais frequentemente utilizadas. Os antígenos injetados intramuscularmente podem formar precipitados persistentes que são dissolvidos e reabsorvidos de maneira relativamente lenta. Existem alternativas de formulações não invasivas, as quais permitem a administração pelo próprio paciente ou por outra pessoa sem necessidade de treinamento. ${ }^{2}$

A pele constitui um ambiente imunológico acessível e competente e um alvo atrativo como sítio de vacinação, através da via transcutânea. ${ }^{3}$ Estratégias de imunização não invasivas sobre a pele são alternativas atraentes para o desenvolvimento de vacinas seguras e indolores. A epiderme é povoada por uma rede de células dendríticas (células de Langerhans), potentes células apresentadoras de antígenos capazes de migrar ao linfonodo drenante, onde elas subsequentemente apresentam antígenos aos linfócitos $\mathrm{T} .{ }^{4}$ A pele é, portanto, um microambiente imunologicamente ativo e oferece um potencial único como tecido alvo para imunização. ${ }^{2,5}$

A imunização transcutânea fornece uma via alternativa para vacinação sem uso de seringas e tem várias vantagens sobre vias parenterais. ${ }^{6}$ A simplicidade da imunização transcutânea pode reduzir ou eliminar a necessidade da administração de vacinação por pessoa treinada. Além disso, a aplicação dérmica de adesivos poderia reduzir a incidência de infecções causadas por acidentes com seringas e poderia estabilizar a vacina, facilitando seu uso fora da cadeia de refrigeração. ${ }^{7}$

A imunização transcutânea é um procedimento que pode induzir uma potente resposta proliferativa de células T antígeno específicas. ${ }^{8}$ Algumas proteínas, notadamente exotoxinas adenosina-difosfato ribosiladas, tais com a enterotoxina termolábil (LT heat-labile toxin) de Escherichia coli e a toxina da cólera (subunidade B), são capazes de induzir potente resposta imune e atuar como forte adjuvante para mucosa. ${ }^{9}$ A aplicação de adesivo (patch) contendo LT na pele levou a uma potente resposta imune em humanos. Estudos clínicos de fase II com adesivo de LT contra a diarreia de viajantes induzida pela E. coli mostraram-se promissores. ${ }^{7}{ }^{7}$ Embora somente quantidades ínfimas de proteínas sejam carreadas na epiderme, são suficientes para induzir uma resposta imune. Métodos não invasivos para aumentar a eficácia da absorção do antígeno vacinal incluem o uso de vesículas elásticas, aumentadores de penetração percutânea ionóforos e ultrassom. ${ }^{2}$

$\mathrm{O}$ pigmento da planta Lawsonia inermis, popularmente conhecida com henna, tem sido empregado na confecção de tatuagens e utilizado na tintura de cabelos. Essa planta possui o porte de arbusto e cresce com abundância em países de clima quente. É encontrada na Índia, Paquistão, Pérsia, Egito e em outros países norte africanos e asiáticos. A planta é popularmente conhecida pelos efeitos cosméticos e, principalmente, por suas propriedades terapêuticas, entre elas ação antibiótica e protetora da pele. Pigmentos de plantas têm sido utilizados para vários propósitos. Populações indígenas utilizam pigmentos de alguns tipos de plantas, como o urucum, para pintura corporal; e populações urbanas os utilizam na confecção de tatuagens não permanentes. Esses pigmentos têm mostrado baixa ou nenhuma toxidade e são eliminados espontaneamente. O objetivo deste estudo foi avaliar o potencial do pigmento de $L$. inermis como carreador de antígenos administrados por via transcutânea.

\section{MÉTODOS}

\section{Obtenção e preparação da suspensão de Lawsonia inermis}

O pó da folha de L. inermis foi obtido em estabelecimentos que comercializam plantas medicinais. $\mathrm{O}$ pó da planta foi ressuspendido em água até a obtenção de uma pasta escura. Uma parte dessa preparação recebeu antígeno bruto de Paracoccidioides brasiliensis ou albumina sérica bovina (BSA: bovine serum albumin) (Sigma-Aldrich, St. Louis, Estados Unidos) nas concentrações de 1,10 e $50 \mathrm{mg}$ por $\mathrm{mL}$, enquanto outra serviu de controle sem adição dos mesmos.

\section{Preparação de antígenos}

Nos ensaios de imunoadsorção enzimática (ELISA - Enzyme-Linked Immunosorbent Assay) e de proliferação linfocitária foi utilizado antígeno solúvel de $P$. brasiliensis preparado de acordo com Camargo et al. ${ }^{10}$ Outro antígeno utilizado nos experimentos foi a BSA. 


\section{Animais}

Cento e oitenta e um camundongos Swiss fêmeas de 8 a 10 semanas de idade foram obtidos do biotério institucional e mantidos em condições livre de patógenos e controladas para temperatura e luminosidade. O projeto foi aprovado pelo Comitê de Ética Animal institucional, protocolo 23087.000984/2009-68.

\section{Desenho experimental}

\section{Imunização transcutânea via pele do abdômen}

Foram utilizados três grupos de sete animais cada, a saber: grupo controle com adição apenas de pigmento de L. inermis e tampão fosfato-salino (PBS - phophate buffered saline); grupo teste com adição de pigmento de $L$. inermis e antígeno bruto de $P$. brasiliensis nas concentrações de 1,10 ou $50 \mathrm{mg} / \mathrm{mL}$; e grupo controle de imunização, cujos animais receberam subcutaneamente antígeno bruto de $P$. brasiliensis em adjuvante incompleto de Freund. Após anestesia com injeção intraperitoneal com $0,15 \mathrm{~mL}$ de quetamina $(100 \mathrm{mg} / \mathrm{mL})$ e $2 \%$ de xilazina (vol/vol) em solução salina, foram retirados os pelos de uma área do abdômen com aproximadamente $2,5 \mathrm{~cm}^{2}$, com uso de barbeador elétrico. Cuidado especial foi tomado no sentido de se evitar cortes na pele. A seguir, os animais receberam sobre a pele depilada uma suspensão de pigmento de L. inermis (200 mg do pó de L. inermis ressuspendido em $1 \mathrm{~mL}$ de solução de antígeno bruto de $P$. brasiliensis nas concentrações de 1,10 ou $50 \mathrm{mg} / \mathrm{mL}$ ). Os animais controle receberam os pigmentos desprovidos de antígenos. Os animais do grupo controle de imunização receberam $100 \mu \mathrm{L}$ da suspensão de antígeno $(2,5 \mathrm{mg} / \mathrm{mL}) \mathrm{em}$ adjuvante de Freund. Cerca de 30 minutos após a administração do antígeno, o excesso do pigmento contendo ou não a suspensão antigênica foi retirado com auxílio de algodão embebido em solução salina fisiológica. Os animais foram examinados após 1, 24 e $48 \mathrm{~h}$ para pesquisar sinais irritativos (eritema) ou edema no local. O procedimento foi realizado três vezes, com intervalo de sete dias entre as imunizações.

Os animais foram anestesiados e eutanasiados por punção cardíaca 28 dias após a aplicação do antígeno. O sangue foi coletado para obtenção de soro e avaliação da produção de anticorpos específicos para antígenos do P. brasiliensis pelo método de ELISA indireto. Foram coletadas células do baço para avaliação do perfil das citocinas interferon gama (IFN- $\gamma$ ) e interleucina 4 (IL-4), assim como produção de óxido nítrico (NO: nitric oxide). Foram realizadas pelo menos duas repetições de cada experimento.

\section{Imunização transcutânea via pele da orelha e efeito do dimetilsulfóxido (DMSO)}

Neste grupo de experimentos utilizou-se a pele da orelha, escolhida por ser desprovida de pelos e por possuir extrato córneo mais fino. A imunização transcutânea na pele da orelha foi realizada de maneira semelhante à descrita anteriormente para a pele do abdômen. Entretanto, introduziu-se como modificação o uso de DMSO na preparação do pigmento de $L$. inermis. O DMSO, que é um tensoativo/surfactante usado normalmente para dissolver substâncias com caráter apolar, foi utilizado, na concentração de 5\%, em uma tentativa de facilitar a dissolução do pigmento e sua passagem pela pele. Vinte e um animais foram divididos em três grupos de sete animais cada: grupo controle, contendo o pigmento de L. inermis e DMSO; grupo teste, contendo o pigmento, DMSO e o antígeno BSA; e grupo controle do antígeno, contendo o pigmento e o antígeno BSA. Depois de sacrificados, foram retiradas as orelhas dos animais que receberam o pigmento, e mantidas em solução de formol a $10 \%$, para posterior análise histológica do tecido. Anticorpos específicos para BSA presentes no soro de animais controle e imunizados foram medidos pelo método de ELISA indireto.

\section{Ensaio da imunoadsorção enzimática para detecção de anticorpos específicos}

Anticorpos antiantígenos da classe imunoglobulina (Ig) $\mathrm{G}$ foram medidos no soro de animais do grupo controle e do grupo de estudo. Resumidamente: placas de 96 poços de fundo chato (Nunc, Rochester, Estados Unidos) foram sensibilizadas com $100 \mathrm{~mL}$ a $5 \mu \mathrm{g} / \mathrm{mL}$ do antígeno diluído em tampão carbonato-bicarbonato $0,1 \mathrm{M}(\mathrm{pH} 9,6)$ a $4^{\circ} \mathrm{C}$ por $15 \mathrm{~h}$. A seguir, as placas foram lavadas em PBS-Tween $0,05 \%$ e bloqueadas com $150 \mathrm{~mL}$ de leite em pó desnatado a 3\% em PBS-Tween; $100 \mathrm{~mL}$ de diferentes diluições do soro provenientes dos dois grupos foram adicionados nos poços por $1 \mathrm{~h}$ a $37^{\circ} \mathrm{C}$. Após incubação e nova lavagem com PBS-Tween, foram adicionados $100 \mathrm{~mL}$ de conjugado peroxidase antianticorpo de camundongo diluído 1:15.000 (Sigma-Aldrich, St. Louis, Estados Unidos). As placas foram incubadas por $1 \mathrm{~h}$ a $37^{\circ} \mathrm{C}$. Após nova lavagem com PBST, adicionou-se $0,4 \mathrm{mg} / \mathrm{mL}$ do substrato OPD (Sigma-Aldrich, St. Louis, Estados Unidos) em tampão citrato pH 5,0 e $40 \mu \mathrm{l}$ de $\mathrm{H}_{2} \mathrm{O}_{2}$ $30 \%$. Em cerca de 10 minutos a reação foi paralisada com adição de $30 \mathrm{~mL}$ de $\mathrm{H}_{2} \mathrm{SO}_{4} 2 \mathrm{~N}$. A leitura de cor 
foi feita a $490 \mathrm{~nm}$ em leitor de ELISA (Zenith200rt, Cambridge, Reino Unido). Os soros foram testados em duplicatas e foi realizado controle interno em todas as placas para testar a especificidade do conjugado aos anticorpos murinos.

\section{Cultivo de esplenócitos para produção de citocinas em sobrenadantes de cultura}

Baços de animais do grupo de estudo e do grupo controle foram desestruturados em condições assépticas e $2 \times 10^{5}$ esplenócitos por poço foram cultivados em placas de 24 poços de fundo chato estéreis em meio de cultura RPMI 1640 contendo 1,6\% de L-glutamina (estoque de $200 \mathrm{mM}$ ), 3\% de uma mistura de antibióticos (100 U/mL penicilina $+100 \mu \mathrm{g} / \mathrm{mL}$ estreptomicina) e $10 \%$ de soro fetal bovino inativado na presença de $5 \mu \mathrm{g} / \mathrm{mL}$ de antígeno de $P$. brasiliensis. As placas foram incubadas por cinco dias a $37^{\circ} \mathrm{C}$ em incubadora com $5 \%$ de $\mathrm{CO}_{2}$. No quinto dia de cultura o sobrenadante foi coletado e estocado em freezer a $-20^{\circ} \mathrm{C}$ para posterior dosagem das citocinas IFN- $\gamma$ e IL-4 e de NO. Todo o procedimento foi realizado em capela de fluxo laminar.

\section{Quantificação de óxido nítrico em sobrenadantes de cultura}

A avaliação das concentrações de NO foi realizada pela medida de nitrito $\left(\mathrm{NO}_{2}^{-}\right)$nos sobrenadantes das culturas de esplenócitos dos animais vacinados e controle: $100 \mathrm{~mL}$ das amostras de sobrenadantes de cultura e $100 \mathrm{~mL}$ do reagente de Griess foram pipetados em placas de 96 poços, em duplicata, e incubados à temperatura ambiente por 10 minutos. A seguir foi determinada a absorbância a $540 \mathrm{~nm}$ em leitor de ELISA (Zenith200rt, Cambridge, Reino Unido). Os resultados expressos em mM foram determinados após a extrapolação de valores obtidos de uma curva padrão realizada com nitrito de sódio $\left(\mathrm{NaNO}_{2}\right)$ para cada placa. O reagente de Griess foi preparado no momento do uso, homogeneizando partes iguais de sulfanilamida a $1 \%$ em $\mathrm{H}_{3} \mathrm{PO}_{4} 2,5 \%$ (Merck, Darmstadt, Alemanha) e de naftilenodiamina (Sigma-Aldrich, St. Louis, Estados Unidos) $0,1 \%$ em água bidestilada. ${ }^{11}$

\section{Detecção de citocinas}

As citocinas IFN- $\gamma$ e IL-4 foram quantificadas através do ensaio ELISA de captura. Foram utilizados anticorpos apropriados e padronizados para as dosagens de citocinas. O ensaio consistiu basicamente em adicionar $100 \mu \mathrm{L}$ de anticorpo monoclonal anticitocina por poço diluído em PBS-Tween 20, 0,05\% por $18 \mathrm{~h}$ a $4^{\circ} \mathrm{C}$. Após incubação, as placas foram lavadas e bloqueadas com $200 \mu \mathrm{L}$ PBS-Tween $20 \%$ por $1 \mathrm{~h}$ à temperatura ambiente e, em seguida, incubadas com amostras de sobrenadantes frescos diluídos em $2 \%$ de soro fetal bovino em solução de PBS-Tween 20 $0,05 \%$, por $3 \mathrm{~h}$ à temperatura ambiente. Paralelamente, concentrações conhecidas de citocinas recombinantes, diluídas em PBS-Tween 20 0,05\% em soro fetal bovino, foram adicionadas às placas como controle para se estabelecer curva padrão. Posteriormente adicionouse um segundo anticorpo monoclonal conjugado com hapteno 4 hydroxy-5-iodo-3-nitro-phenacetyl (NIP), em $0,2 \%$ de BSA em PBS-Tween por $1 \mathrm{~h}$ a $25^{\circ} \mathrm{C}$. Em seguida foi adicionado um anticorpo monoclonal marcado com peroxidase (J4-HRP) que reconhece o hapteno NIP diluído em 0,2\% de BSA em PBS-Tween por $1 \mathrm{~h}$ a $25^{\circ} \mathrm{C}$. Após lavagem, adicionou-se o substrato ortofenilenodiamino (OPD) (Sigma-Aldrich, St. Louis, Estados Unidos) e a cor desenvolvida foi medida a 490 nm em um leitor de ELISA automático.

\section{Análise estatística}

Média e desvio padrão foram calculados usando o programa SISVAR. As diferenças estatísticas entre os grupos foram analisadas por análise de variância (ANOVA) e por teste de Mann-Whitney; $p<0.05$ foi considerado estatisticamente significante.

\section{RESULTADOS}

\section{Avaliação da resposta imune humoral}

Os dados das médias da densidade óptica para cada grupo de animais vacinados por via transcutânea na pele do abdômen estão representados na Tabela 1 . Nenhum dos grupos imunizados por via transcutânea com o antígeno de $P$. brasiliensis apresentou resposta significativa de anticorpos IgG em relação aos animais do grupo controle negativo. Foi observada uma resposta fraca nos animais imunizados subcutaneamente na presença de adjuvante de Freund $(p=0,0006)$. Os resultados sugerem que o protocolo de vacinação por via transcutânea com antígeno bruto de P.brasiliensis não foi capaz de induzir a produção de anticorpos específicos nas condições testadas.

Em relação à imunização via pele da orelha e efeito do DMSO adicionado ao pigmento de $L$. inermis, os dados sugerem, igualmente, que não houve imunização efetiva contra o antígeno BSA (Figura 1). Nas condições empregadas, o DMSO não provocou nenhum efeito inflamatório, e também não apresentou nenhum efeito aditivo sobre a imunização transcutânea. 
A análise histopatológica mostrou que o pigmento não penetrou nas camadas mais profundas da pele (dados não mostrados). $\mathrm{O}$ controle interno realizado em todas as placas comprovou a especificidade do conjugado aos anticorpos murinos.

Tabela 1. Média e desvio padrão da densidade óptica usando soros de diferentes grupos de animais imunizados com diferentes concentrações de antígenos de $P$. brasiliensis por via transcutânea na pele do abdômen na presença de pigmentos de L. inermis.

\begin{tabular}{lcc}
\hline \multicolumn{1}{c}{ Grupo de animais } & Média + DP & p \\
\hline $\begin{array}{l}\text { Animais imunizados na presença de } \\
\text { pigmento de } L \text {. inermis com PBS } \\
\text { (controle negativo) }\end{array}$ & $0,045 \pm 0,007$ & ---- \\
$\begin{array}{l}\text { Animais imunizados com } 1 \mathrm{mg} / \mathrm{mL} \text { de } \\
\text { antígeno em presença de pigmento de }\end{array}$ & $0,044 \pm 0,011$ & 1,0 \\
$\begin{array}{l}\text { L. inermis } \\
\text { Animais imunizados com } 10 \mathrm{mg} / \mathrm{mL} \text { de } \\
\text { antígeno em presença de pigmento de }\end{array}$ & $0,048 \pm 0,007$ & 0,62 \\
$\begin{array}{l}\text { L. inermis } \\
\begin{array}{l}\text { Animais imunizados com } 50 \mathrm{mg} / \mathrm{mL} \text { de } \\
\text { antígeno em presença de pigmento de }\end{array}\end{array}$ & $0,053 \pm 0,020$ & 0,7104 \\
$\begin{array}{l}\text { L. inermis } \\
\text { Animais imunizados com adjuvante de }\end{array}$ & & \\
$\begin{array}{l}\text { Freund por via subcutânea (controle } \\
\text { positivo de imunização). }\end{array}$ & $0,120 \pm 0,104$ & 0,0006 \\
\hline
\end{tabular}

Os animais controle de imunização receberam inóculo com antígeno de $P$. brasiliensis $(2,5 \mathrm{mg} / \mathrm{mL})$ em presença de adjunte de Freund (v/v)

DP: desvio padrão; PBS: tampão fosfato-salino (phophate buffered saline)

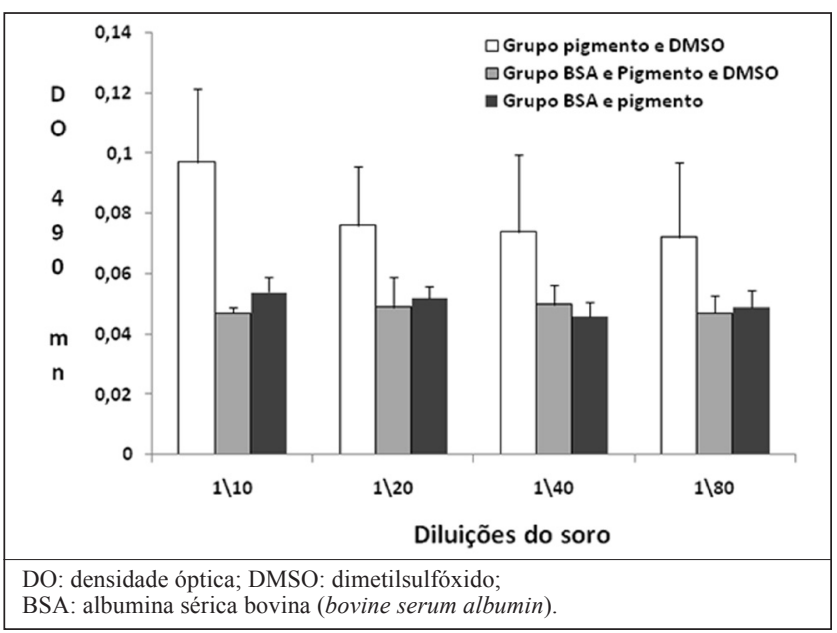

Figura 1. Média e desvio padrão da densidade óptica usando soros de diferentes grupos de animais em esquema de vacinação transcutânea com albumina sérica bovina na pele da orelha, utilizando pigmento de Lawsonia inermis adicionado ou não de dimetilsulfóxido.

\section{Avaliação da reatogenicidade}

$\mathrm{O}$ pigmento de $L$. inermis mostrou-se seguro quando administrado por via cutânea, uma vez que não foram observados sinais inflamatórios (edema e eritema) nos animais manipulados experimentalmente nos tempos propostos.

\section{Quantificação da produção de citocinas em sobrenadantes de cultura}

Não foi detectada diferença significativa na produção de citocinas IFN- $\gamma$ e IL-4 em sobrenadantes de cultura de células provenientes de animais vacinados quando comparados com animais não vacinados (dados não mostrados).

\section{Quantificação de óxido nítrico em sobrenadantes de cultura}

A Figura 2 mostra média e desvio padrão dos resultados da produção de $\mathrm{NO}$ em sobrenadantes de cultura de esplenócitos de animais não estimulados (C) e em células dos animais estimulados por antígeno de P.brasiliensis, quantificados pela presença de nitrito $\left(\mathrm{NO}_{2}^{-}\right)$. Não foram encontradas diferenças entre a produção de $\mathrm{NO}$ entre as culturas controle e estimuladas pelo antígeno.

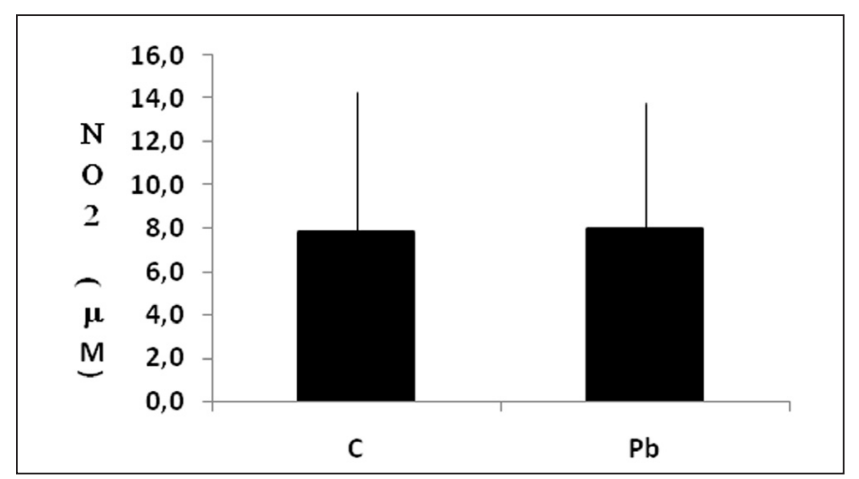

Figura 2. Média da produção de nitritos $\left(\mathrm{NO}_{2}\right)$ em sobrenadantes de cultura de esplenócitos $\left(2 \times 10^{5}\right)$ de animais imunizados por via transcutânea não estimulados $(C)$ e animais estimulados com $5 \mu \mathrm{g} / \mathrm{mL}$ de antígenos do Paracoccidioides brasiliensis $(\mathrm{Pb})$.

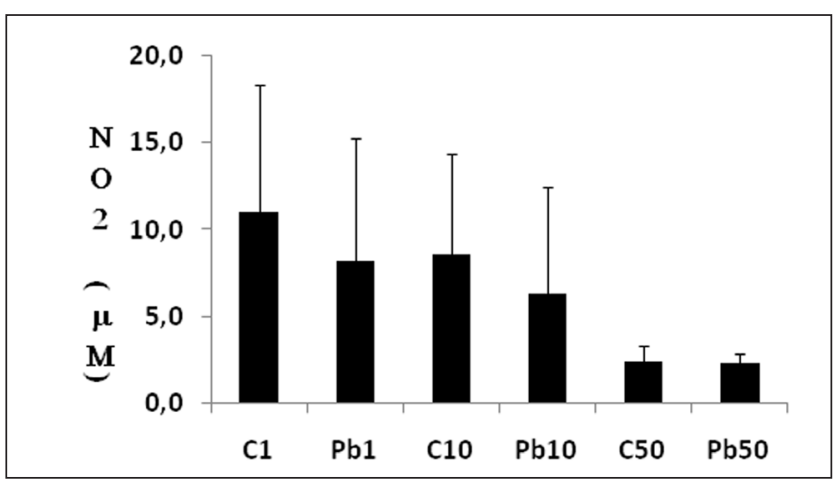

Figura 3. Média da produção de nitritos $\left(\mathrm{NO}_{2}\right)$ em sobrenadantes de cultura de esplenócitos de animais não estimulados $(\mathrm{C})$ e com antígenos do Paracoccidioides brasiliensis $(\mathrm{Pb})$ em diferentes concentrações de antígenos (1, 10 e $50 \mathrm{mg} / \mathrm{mL})$. C1, C10 e C50 representam grupos de animais controle para cada grupo de animais estimulados com 1, 10 e $50 \mathrm{mg} / \mathrm{mL}$ dos antígenos $(\mathrm{Pb})$. 
A Figura 3 mostra a produção de NO nos grupos de animais vacinados com diferentes concentrações de antígeno de $P$. brasiliensis (1, 10 e $50 \mathrm{mg} / \mathrm{mL})$ em comparação com as culturas não estimuladas. Novamente, não foram observadas diferenças na produção de NO nas culturas provenientes dos grupos de animais vacinados com diferentes concentrações de antígeno quando comparados com seus respectivos controles.

\section{DISCUSSÃO}

A imunização transcutânea é um método de vacinação promissor que utiliza aplicação tópica de um antígeno vacinal e adjuvante na pele intacta para induzir uma resposta imunológica; ${ }^{16}$ pode induzir marcante resposta imune mediada por anticorpos e células em animais e em seres humanos. ${ }^{12}$ Produtos bacterianos, notadamente exotoxinas ADP-ribosiladas, tais como a enteroxina termolábil de E. coli e a toxina da cólera (subunidade B), tem sido usados como adjuvantes nesse tipo de imunização. ${ }^{12,16}$ No entanto, o estrato córneo, que é composto por células mortas e lipídios, representa a principal barreira de penetração da pele..$^{3,15}$

Neste estudo trabalhamos com pigmento de L. inermis, planta popularmente conhecida como henna (amplamente empregado para tatuar a pele ou tingir os cabelos), como carreador de antígenos em um esquema de vacinação transcutânea. Não foram observados efeitos adversos induzidos pelo pigmento de henna nos diferentes tempos testados. Casos de dermatite de contato em tatuagens por henna não são incomuns, mas são consequentes ao uso indevido de sais metálicos visando aumentar a pigmentação. ${ }^{17} \mathrm{O}$ esquema de vacinação transcutânea (três imunizações com sete dias de intervalo), usando o pigmento de henna como carreador de antígenos, não induziu à formação de anticorpos específicos, seja aplicado na pele do abdomen, seja aplicado na pele da orelha. Não se pode considerar que o resultado negativo do experimento possa ser devido a erros associados ao protocolo do ensaio de ELISA, uma vez que o controle interno realizado em todas as placas comprovou a especificidade do conjugado aos anticorpos murinos. A adição de DMSO ao pigmento não apresentou nenhum efeito aditivo sobre a imunização. Diferentemente, Heckert et al. ${ }^{18}$ mostraram que um esquema de imunização transcutânea na pele de galinhas utilizando DMSO e DNA plasmidial aumentou a produção de $\operatorname{IgA}$ e $\operatorname{IgM}$ nas lágrimas e no soro de galinhas vacinadas e conferiu imunidade protetora ao desafio.
Não foi observada diferença na produção de NO nem no nível de citocinas entre animais vacinados e controles. Uma possível explicação para estes resultados poderia ser o efeito barreira exercido pela pele aos antígenos proteicos utilizados, os quais possuem peso molecular relativamente alto, o que pode dificultar sua passagem através da pele. O tamanho da molécula parece ter uma relação com seu poder de penetração na pele. A molécula de DNA possui um peso molecular muito menor quando comparada a antígenos proteicos. Em um estudo usando tatuagem mecânica induzida por agulhas e DNA como imunógeno conseguiu-se induzir uma resposta efetiva de anticorpos com imunização realizada através da pele. ${ }^{19}$ Parece que nesse caso a indução de imunidade estaria associada a uma intensa inflamação induzida pela tatuagem com agulhas, o que torna a técnica dolorida e inviável como esquema de vacinação em massa. Outro ponto a ser levantado é a possibilidade de um efeito imunossupressor induzido pelo pigmento, visto que este não induziu nenhum efeito inflamatório. Apesar de não estar diretamente associado, parece ser possível a indução de tolerância em um modelo de imunização transcutânea. ${ }^{20}$

Embora este estudo não tenha obtido sucesso com o uso de henna como carreador de antígenos em um modelo de vacinação transcutânea, esse tipo de imunização baseia-se na premissa de que as respostas imunitárias ao nível de mucosa e sistêmica podem ser iniciadas por estimulação imunológica na superfície da pele e que o papel das toxinas da cólera ou tetânica como adjuvante parece ser crucial para a indução de respostas imunitárias robustas por essa via. ${ }^{12,16}$ Mesmo na ausência de imunoestimuladores de mucosa, foi possível induzir uma potente resposta de anticorpo antígeno específico na pele de ratos, simplesmente prolongando a duração da presença do antígeno. ${ }^{21}$ Apesar de ser um método promissor, outros estudos ainda são necessários para a completa compreensão da resposta imune induzida por imunização transcutânea.

$\mathrm{O}$ pigmento de $L$. inermis mostrou-se seguro quando administrado por via cutânea, uma vez que não foram observados sinais inflamatórios nos animais manipulados experimentalmente. Entretanto, a vacinação transcutânea com antígeno bruto de $P$. brasiliensis suspendido em pigmento de $L$. inermis em camundongos não foi eficaz nas condições testadas.

\section{AGRADECIMENTOS}

A Fundação de Amparo à Pesquisa do Estado de Minas Gerais (FAPEMIG) (APQ-01629-09) e ao Conselho Nacional de Desenvolvimento Cientifico e Tecnológico (CNPq) (501502/2009-2). 


\section{REFERÊNCIAS}

1. Amanna IJ, Slifka MK. Contributions of humoral and cellular immunity to vaccine induced protection in humans. Virology. 2011;411:206-15.

2. Kersten G, Hirschber H. Needle-free vaccine delivery. Exp. Opin. Drug Deliv. 2007;4:459-74.

3. Denis F, Alain S, Ploy MC. New routes of administration: epidermal, transcutaneous mucosal ways of vaccination. Med Sci. 2007;23:379-85.

4. Gerdts V, Mutwiri GK, Tikoo SK, et al. Mucosal delivery of vaccines in domestic animals. Vet Res. 2006;37:487-510.

5. Randolph GJ, Angeli V, Swartz MA. Dendritic-cell trafficking to lymph nodes through lymphatic vessels. Nat Rev Immunol. 2005;5:617-28.

6. Glenn GM, Kenney RT, Hammond SA, et al. Transcutaneous immunization and immunostimulant strategies. Immunol Allergy Clin North Am. 2003;23:787-13.

7. Glenn GM, Flyer DC, Ellingsworth LR, et al. Transcutaneous immunization with heat-labile enterotoxin: development of a needle-free vaccine patch. Expert Rev Vaccines. 2007;6: 809-19.

8. Guebre-Xabier M, Hammond SA, Epperson DE, et al. Immunostimulant patch containing heat-labile enterotoxin from Escherichia coli enhances immune responses to injected influenza virus vaccine through activation of skin dendritic cells. J Virol. 2003;77:5218-25.

9. Fingerut E, Gutter B, Goldway M, et al. B subunit of $E$. coli enterotoxin as adjuvant and carrier in oral and skin vaccination. Vet Immunol Immunopathol. 2006;112(3-4): 253-63.

10. Camargo ZP, Berzaghi R, Amaral CC, et al. Simplified method for producing Paracoccidioides brasiliensis exoantigens for use in immunodiffusion tests. Med Mycol. 2003;41:539-42.

11. Green LC, Wagner DA, Glogowski J, et al. Analyses of nitrate, nitrite and $[15 \mathrm{~N}]$ nitrate in biological fluids. Anal Biochem. 1982;126:131-8.
12. Glenn GM, Scharton-Kersten T, Vassell R, et al. Transcutaneous immunization with bacterial ADPribosylating exotoxins as antigens and adjuvants. Infect Immun. 1999;67:1100-6.

13. Belyakov IM, Hammond SA, Ahlers JD, et al. Transcutaneous immunization induces mucosal CTLs and protective immunity by migration of primed skin dendritic cells. J Clin Invest. 2004;113:998-07.

14. Combadière B, Vogt A, Mahé B, et al. Preferential amplification of CD8 Effector-T cells after transcutaneous application of an inactivated influenza vaccine: a randomized phase I trial. PLoS One. 2010;26;5(5):e10818.

15. Scharton-Kersten T, Yu J, Vassell R, . et al. Transcutaneous Immunization with bacterial ADP-ribosylating exotoxins, subunits, and unrelated adjuvants. Infect Immun. 2000;68:5306-13.

16. Glenn GM, Rao M, Matyas GR, et al. Skin immunization made possible by cholera toxin. Nature. 1998;391:851.

17. Carretero P, Garcés MM, Herrero D, et al. Contact dermatitis due to a henna tattoo. Alergol. Inmunol. Clin. 2000;15: 325-7.

18. Heckert RA, Elankumaran S, Oshop GL, et al. A novel transcutaneous plasmid-dimethylsulfoxide delivery technique for avian nucleic acid immunization. Vet Immunol Immunopathol. 2002;89:67-81.

19. Pokorna D, Rubio I, Müller M. DNA-vaccination via tattooing induces stronger humoral and cellular immune responses than intramuscular delivery supported by molecular adjuvants. Genet Vaccines Ther. 2008;6:4.

20. Ghoreishi M, Dutz JP. Tolerance induction by transcutaneous immunization through ultraviolet-irradiated skin is transferable through $\mathrm{CD} 4+\mathrm{CD} 25+\mathrm{T}$ regulatory cells and is dependent on host-derived IL-10. J Immunol. 2006; 176:2635-44.

21. Naito S, Maeyama J, Mizukami T, et al. Transcutaneous immunization by merely prolonging the duration of antigen presence on the skin of mice induces a potent antigenspecific antibody response even in the absence of an adjuvant. Vaccine. 2007;25:8762-70. 